
\title{
25 Research Soure \\ Direct imaging of the disconnection climb mediated point defects absorption by a grain boundary
}

Jiake Wei

The University of Tokyo

Bin Feng

The University of Tokyo https://orcid.org/0000-0002-4306-2979

\section{Eita Tochigi}

The University of Tokyo

\section{Naoya Shibata}

University of Tokyo https://orcid.org/0000-0003-3548-5952

Yuichi lkuhara ( $\nabla$ ikuhara@sigma.t.u-tokyo.ac.jp )

University of Tokyo https://orcid.org/0000-0003-3886-005X

\section{Article}

Keywords: grain boundaries, radiation resistance, microscopy

Posted Date: May 26th, 2021

DOI: https://doi.org/10.21203/rs.3.rs-537668/v1

License: (c) (1) This work is licensed under a Creative Commons Attribution 4.0 International License. Read Full License

Version of Record: A version of this preprint was published at Nature Communications on March 18th, 2022. See the published version at https://doi.org/10.1038/s41467-022-29162-2. 


\section{Abstract}

Grain boundaries (GBs) have been considered to be the effective sinks for point defects, which improve the radiation resistance of materials. However, the fundamental mechanisms of how the GBs absorb and annihilate point defects under irradiation at atomic scale are still not well understood. With the aid of the atomic resolution scanning transmission electron microscope (STEM), we experimentally investigated the atomistic mechanism of point defects absorption by a $\sum 31 \mathrm{~GB}$ in a-Al203 under high energy electron beam irradiation. It is shown that a disconnection pair was formed, during which all the Al atomic columns were tracked by STEM imaging. We demonstrated that the formation of the disconnection pair is proceeded with disappearing of atomic columns in the GB core, which suggests that the GB absorbed vacancies. Such point defect absorption is attributed to the disconnection climb motion in mesoscopic scale. These experimental results provide an atomistic understanding of how GBs improve the radiation resistance of materials.

\section{Full Text}

Due to technical limitations, full-text HTML conversion of this manuscript could not be completed. However, the manuscript can be downloaded and accessed as a PDF.

\section{Supplementary Files}

This is a list of supplementary files associated with this preprint. Click to download.

- Movie1.mp4

- SupplementaryMaterials0512.docx 